\title{
OPTIMIZATION OF MANUFACTURING PROCESSES USING MODERN AUTOMATED CNC MILLING MACHINES
}

\author{
Borivoj Novaković ${ }^{1}$, Mića Đurđev ${ }^{1}$, Ljiljana Radovanović ${ }^{1}$, James G. Speight ${ }^{2}$ \\ ${ }^{1}$ University of Novi Sad, Technical faculty "Mihajlo Pupin", Zrenjanin, Serbia \\ ${ }^{2} \mathrm{CD} \&$ W Inc., Laramie, Wyoming, USA
}

\begin{abstract}
:
The subject of this research is based on the optimization of the manufacturing process using modern automated CNC milling machines. The problem that has generally emerged on the world market is to fulfil goals dictated by the modern era which are reflected in quality, time domain and complexity of a manufacturing process. Adopting modern CNC milling machines, it seeks to maximize production optimization, mostly from the aspect of manufacturing times with occurring indirect factors that affect the overall optimization. The idea of this study is based on a comparison of efficiency and effectiveness between traditional systems which are still being used in production plants and modern - automated systems that slowly overtake the role as a leader in all production spheres.
\end{abstract}

\section{ARTICLE HISTORY}

Received: 20.11.2018.

Accepted: 03.12.2018.

Available: 31.12.2018.

\section{KEYWORDS}

Optimization, automation, CNC milling machine, traditional systems, manufacturing

\section{INTRODUCTION}

In the age of modern information technologies, the degree of automation has rapidly begun to converge towards complete implementation of these types of systems in all branches of industry. New technologies speed up the production process by using various software systems, starting from the preparation of production, through production and final production control. The accent here is placed on manufacturing engineering as a scientific field which is for a longer period of time dealing with the complete implementation of modern automated manufacturing systems in order to accelerate and improve production processes. As far as the optimization of manufacturing processes is concerned, the preparation of production plays a major role in this domain which largely shortens the manufacturing time and makes the entire manufacturing process faster. Within production systems, a dominant role in meeting market requirements for novel and customized products belongs to the processes of design, planning, control and manufacturing [1]. The basic task of the technological preparation of production is to study product design and manufacturing capabilities of a production system and according to that provide the optimal manufacturability of product design and determine the most effective manufacturing methods and techniques for rational utilization of manufacturing resources within the production process [2]. Two main tasks of the technological preparation of production are process planning and optimization of process plans [3]. Besides the preparation of production, the highest level of optimization of manufacturing processes through automated CNC milling machines is achieved by considering the segment of cutting tool alternatives that largely affects timing aspects of manufacturing as well as the segment that is directly related to energy savings, as an economic factor of manufacturing optimization.

\section{THE PREPARATION OF PRODUCTION FOR CNC MILLING PROCESSES}

When it comes to the preparation of production as one of the preparatory aspects of the production itself, it is necessary to mention 
that in industry the preparation is generally consisted of product design and technological preparation of production. Two forms of preparation are mutually compatible, following one another.

In this paper, modern software systems AutoCAD 2016 and CATIA V5 were used for performing the entire preparation of production for the designed part.

These systems are mostly used for design, modelling, sketching as well as test software. CAD and CAM systems are usually a combination of software in which CAD represents computer aided design, while CAM is computer aided manufacturing [4].

Figure 1 shows the 3D model of prismatic coupling that belongs to the product design segment of the preparation of production.

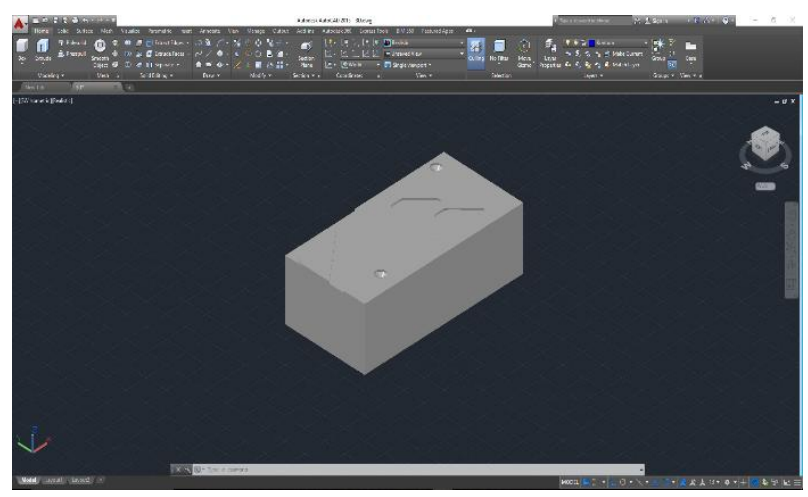

Fig. 1. 3D model of prismatic coupling [5]

Design of prismatic coupling was performed in the AutoCAD software where the 3D modelling was directly performed in order to facilitate the manufacturing process and to provide a precise visualization of the part. Based on the 3D model, a technical drawing can be made with all corresponding parameters.

When it comes to the technological preparation of production, due to its complexity in contrast to product design, it requires more attention in this study. The experiences from manufacturing and latest research studies show that approaches to the development of technologies of required and sufficient quality should be built on the principles of systematic approach [6].

CAPP systems have a complex task that involves the integration with other functions in an enterprise, such as financial flows, production planning, manufacturing resource planning and management, quality control, etc. The model of this integration in production environment can be seen in Figure 2 [7].
Computer aided process planning (CAPP) is based on transforming input in the form of engineering drawings and/or product models into output which should consist of process selection and identification, process and operation sequencing as well as other information necessary to transform raw material into a finished product [10].

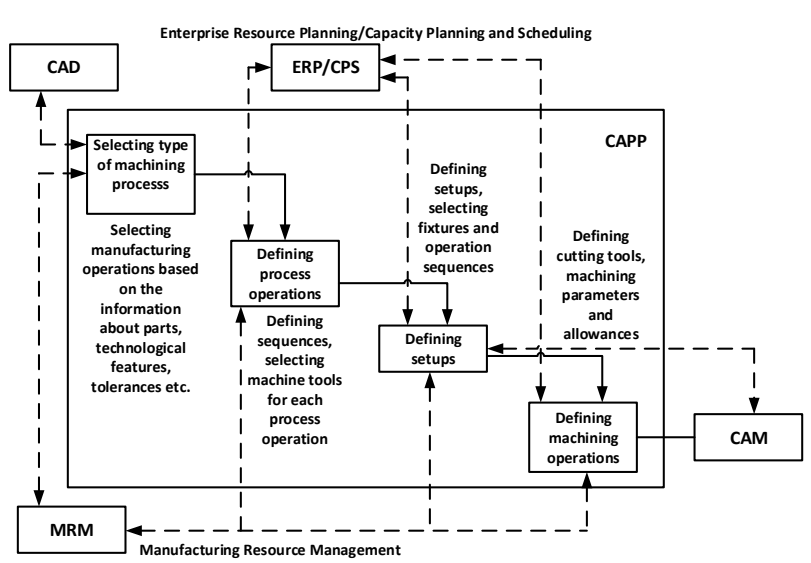

Fig. 2. Model of integration of CAPP system $[8,9]$

\section{OPTIMIZING MANUFACTURING USING AUTOMATED SYSTEM}

By implementing the aforementioned methods in the preparation of production, manufacturing process can be optimized by directing towards the minimization of errors to a minimum percentage. In that way, delays that occur during the manufacturing on CNC milling machines may be avoided.

When conducting the study on optimization of processes on CNC milling machines and determining advantages derived from the use of this approach, the primary goal of this research has to be determined. Primary factors in this paper are manufacturing time as well as economic factors that are reflected through indirect aspects form manufacturing. Indirect factors primarily consider the manufacturing cost starting from the cost of energy consumption to the machine operator costs.

The research is based on a comparative analysis of use of modern automated CNC milling machines on one side and traditional universal milling machines on the other side in the case of large scale production.

The first influential factor is the manufacturing time where cutting tool changes are adopted as one of the relevant parameters for $\mathrm{CNC}$ and traditional milling machines. CNC milling machines have installed automatic tool change in their 
machine control unit, including toolbox that is automatically positioning above the workpiece.

Figure 3 represents the automatic tool changer that is used for CNC milling machines.

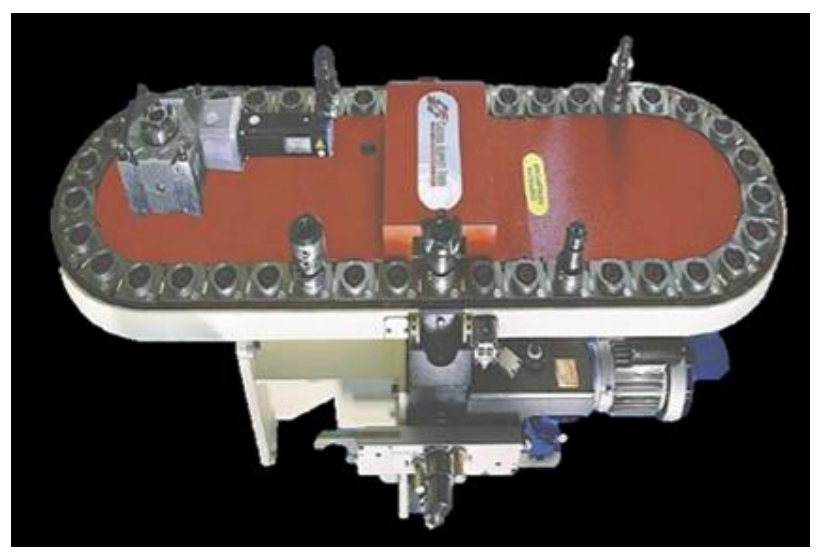

Fig. 3. Automated tool changer [5]

If solely this parameter was considered as the difference in time domain, it can be determined that the difference in manufacturing time exists only due to tool change time. For the given instance, tool change is achieved only once, using 2 tools for 3 process operations. Based on this instance, standard time deviation is approximately 60 seconds, i.e. one minute.

Using this case for large-scale production problems, for example 1,000 parts, the difference would be calculated in the following way:

\section{Traditional manufacturing technologies}

$$
\begin{gathered}
T_{u k}=1,000 \times 75=75,000 \mathrm{~s} \\
T_{u k}=1,250 \mathrm{~min} \cong \mathbf{2 1} \mathbf{h}
\end{gathered}
$$

\section{Modern manufacturing technologies}

$$
\begin{gathered}
T_{u k}=1,000 * 7=7,000 \mathrm{~s} \\
T_{u k}=117 \mathrm{~min} \cong \mathbf{1 . 9 5} \mathbf{h}
\end{gathered}
$$

Taking this calculation into account, it can be noted that the difference in time domain between these two manufacturing technologies considering only tool changes equals almost 19 hours. For these reasons, traditional manufacturing technologies are hardly imagined to be implemented in large-scale and mass production.

For these costs, an important issue that should also be considered is to make a parallel comparison between energy consumptions for CNC and traditional milling machines. The main reason for this comparison, as it will be stated in the following text, is due to much higher utilization level of CNC milling machines in contrast to traditional milling machines. $440 \mathrm{~W}$ CNC milling machine is used in this study with working parameters that match $2 \mathrm{~kW}$ traditional milling machines. In other words, $440 \mathrm{~W}$ milling machine utilization level is able to achieve 50 to 3,000 rpm, which is almost inconceivable for traditional machines. The upper limit of 3,000 rpm match with $2 \mathrm{~kW}$ universal milling machines. Considering that relation, comparison on the basis of energy consumption can be made.

Figure 4 represents the CNC milling machine adopted for manufacturing time optimization within this study.

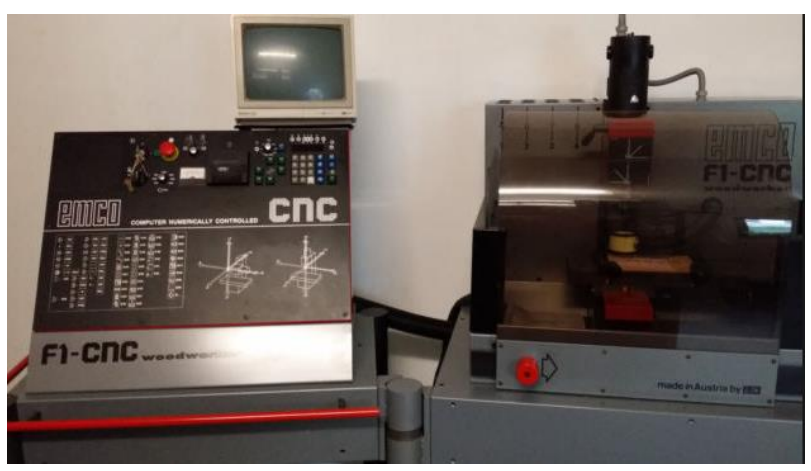

Fig. 4. CNC EMCO F1 COMPACT milling machine [5]

Table 1. Calculated energy consumption [5]

\begin{tabular}{|c|c|c|c|}
\hline Machine & $\begin{array}{c}\text { Power } \\
\text { (W) }\end{array}$ & $\begin{array}{c}\text { kWh cost } \\
\text { (RSD) }\end{array}$ & $\begin{array}{c}\text { Total cost } \\
\text { (RSD) }\end{array}$ \\
\hline $\begin{array}{c}\text { CNC milling } \\
\text { machine }\end{array}$ & 440 & 5.108 & 2.25 \\
\hline $\begin{array}{c}\text { Traditional } \\
\text { universal } \\
\text { machine }\end{array}$ & 2,000 & 7.658 & 15.316 \\
\hline
\end{tabular}

Table 1 shows the data on energy consumption in one working hour. Let us assume that one working day has 8 active hours, the energy consumption for CNC milling machine during one working day would be:

\section{$\mathrm{CNC}=2.25 \mathrm{RSD} \times 8 \mathrm{~h}=18 \mathrm{RSD}$ per working day}

while for traditional universal machines, the energy consumption would be much higher:

$$
\begin{gathered}
\text { TUG }=15.316 \times 8 \mathrm{~h}=\mathbf{1 2 2 . 5 3} \text { RSD per working } \\
\text { day }
\end{gathered}
$$

If consumption is taken on a monthly level, it would be:

$$
\begin{aligned}
& \mathrm{CNC}= 18 \text { RSD per working day } \times 24 \text { working } \\
& \text { days }=\mathbf{4 3 2} \text { RSD per month }
\end{aligned}
$$

while for traditional machines: 
TUG = 122.53 RSD per working day $x 24$ working days $=$ 2,940.72 RSD per month

Figure 5 shows the power profile for the CNC machine within the machining process.

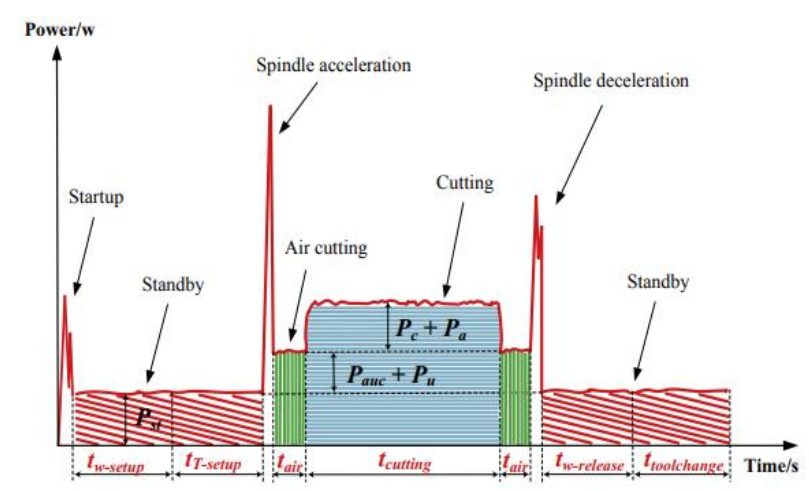

Fig. 5. Power profile for CNC machines during a machining process [11]

The profile from the Figure 4 shows that the cutting stage has the highest impact on energy consumption while the highest power is required for machine start-up and spindle acceleration/deceleration but, due to their short time requirement, they are considered negligible.

\section{RESEARCH RESULTS}

Through this study, the parameters that mostly contribute to optimization of the manufacturing process are considered using modern automated CNC milling machines. Indicators that authors have emphasized are energy consumption, manufacturing time through indirect parameters that affect timing aspect. Indirect impacts on manufacturing time are certainly the preparation of production as the initial stage and the tool change which showed to be a good parameter for the optimization of manufacturing process. Preparation of production assumes all the segments and parameters required to be precized and considered in order to perform manufacturing process in the most quality and efficient way. The problem for traditional preparations was in the time period which in some cases lasted too long and, in addition, preparation of production was not precisely considered with possible omission of certain steps of the preparation. All this leads to decrease in quality and increase in the time period of an entire manufacturing process. Modern manufacturing processes require high accuracy and speed which at some point resulted in the growing development of automated systems. If comparative analyses of the research in this paper are considered, it can be concluded that the preparation of production for CNC manufacturing technologies directly decreases the overall production time. The greatest advantage reflects in the product design stage as well as the stage of process planning which is, among other activities, employed for determining tool candidates which affects automated tool changes and therefore reduce manufacturing time up to 20 times in largescale production.

If we assume that the labour market is based on the Republic of Serbia, the savings in large-scale production from the aspect of human factor would be:

$$
\mathrm{X}=19 \mathrm{~h} \times 143 \mathrm{RSD}=\mathbf{2 , 7 1 7} \mathrm{RSD}
$$

However, if savings in energy consumption are taken into account in addition to human factor, they would be:

- Costs of traditional milling machines in relation to the modern:

$$
\mathrm{X}=19 \mathrm{~h} \times 7.658 \mathrm{RSD}=\mathbf{1 4 5 . 5 0} \mathrm{RSD}
$$

The energy savings in relation to the cost of human factor is almost negligible, but if these 19 hours are used in a constant time period, then the savings would increase according to the working hours which results in the implementation of modern CNC manufacturing technologies and therefore optimization of manufacturing process.

Savings from the aspect of manufacturing time and the preparation of production are mostly reflected in the domain of tool changes. Automated manufacturing systems also ensure automated tool changes with possible auto-mode for certain types. In that way, tool change time in one process operation can be reduced. According to the research studies, tool changes on modern CNC machines last between 5 to 8 seconds, while on traditional machines around 60 to 90 seconds is required. The resulting time clearly says what difference may occur in large-scale and mass production only considering tool changes. It is also shown that the savings for this process operation equal around 19 hours in large-scale production of 1,000 parts. These reasons show that automated manufacturing systems find their application in these types of production and also process operations should be brought to a higher level of automation.

When observing manufacturing times, it can be noted that the segment of the preparation of production takes more time for modern manufacturing technologies comparing to 
traditional ones. Such information says that the preparation of production is more complex and on higher quality level for modern technologies particularly due to reason all process operations are predefined while for traditional technologies most activities in the preparation of production are carried out on machines during the manufacturing process.

Savings in the cost of human factor for modern manufacturing technologies equal around 2700 RSD for 19 hours of saved time in large-scale production.

\section{CONCLUSION}

In order to respond to modern market demands, the need for more practical manufacturing technologies with higher degree of productivity, manufacturability, profitability has emerged. To fulfil and integrate all these needs it was necessary to introduce an appropriate level of manufacturing automation. Automation of manufacturing technologies primarily refer to the automation of the entire production system from the aspect of product design and technological preparation of production to manufacturing itself and all secondary stages that comes after.

CNC manufacturing technologies represent only one segment of automated manufacturing systems that is used in modern manufacturing process within the domain of material removal technologies. CNC technologies largely contribute to the development of large-scale, mass and batch production. The greatest contribution of modern CNC technologies reflects in the time from the initial to final stage where the time of the entire machining process is reduced in contrast to traditional technologies and where predefined preparation of production reduces the scope of activities required to be completed during the machining itself.

\section{REFERENCES}

[1] X. Xu, L. Wang, S.T. Newman, Computer-Aided Process Planning - A Critical Review of Recent Developments and Future Trends. International Journal of Computer Integrated Manufacturing, 24 (1), 2011: 1-31.

https://doi.org/10.1080/0951192X.2010.518632

[2] D. Lukić, M. Milošević, A. Antić, S. Borojević, M. Ficko, Multi-criteria selection of manufacturing processes in the conceptual process planning. Advances in Production
Engineering and Management, 12 (2), 2017: 151-162.

https://doi.org/10.14743/apem2017.2.247

[3] D. Lukić, M. Milošević, J. Vukman, M. Đurđev, A. Antić, Applying precedence relationships and CAD/CAM simulation in time-based optimization of process planning. Applied Engineering Letters, 2 (4), 2017: 130-138.

[4] D. Letić, E., Desnica, Engineering graphics I. University of Novi Sad, Technical faculty.

[5] B. Novaković, Optimization of the technological process of milling staples of polyester in the preparation stage of production (MS.C. Thesis), University of Novi Sad, Technical faculty "Mihajlo Pupin", Zrenjanin, Serbia, 2018.

[6] D. Zelenović, Technology of organization of industrial systems - enterprises. University of Novi Sad, Faculty of Technical Sciences, Novi Sad, Serbia, 2005.

[7] S. Borojević, Development of an System for Simultaneously Product and Process Planning Design (Ph.D. Thesis), University of Novi Sad, Faculty of Technical Sciences, Novi Sad, Serbia, 2015.

[8] M. Milošević, Collaborative system for designing technological processes for manufacturing products based on Internet technologies (Ph.D. Thesis), University of Novi Sad, Faculty of Technical Sciences, Novi Sad, Serbia, 2012.

[9] X. G. Ming, J. Q. Jan, X. H. Wang, S. N. Li, W. F. Lu, Q. J. Peng, Y. S. Mad, Collaborative Process Planning and Manufacturing in Product Lifecycle Management. Computers in Industry, 59 (2-3), 2008: 154-166.

https://doi.org/10.1016/i.compind.2007.06.012

[10] B. Kulvatunyou, R. A. Wysk, H. B. Cho, A. Jones, Integration Framework of Process Planning Based on Resource Independent Operation Summary to Support Collaborative Manufacturing. International Journal of Computer Integrated Manufacturing, 17 (5), 2004: 377-393.

https://doi.org/10.1080/09511920310001607104

[11] L. Linglin, L. Congbo, T. Ying, L. Li, An integrated approach of process planning and cutting parameter optimization for energyaware CNC machining. Journal of Cleaner Production, 162 (-), 2017: 458-473.

https://doi.org/10.1016/i.jclepro.2017.06.034 